\title{
Effects of chronic sodium salicylate feeding on the impaired glucagon and epinephrine responses to insulin-induced hypoglycaemia in streptozotocin diabetic rats
}

\author{
D. G. Patel and K.A.Skau \\ Division of Pharmacology and Medicinal Chemistry, College of Pharmacy, University of Cincinnati Medical Center, Cincinnati, Ohio, USA
}

\begin{abstract}
Summary. The potential role of endogenous prostaglandins in glucagon and epinephrine responses to insulin-induced hypoglycaemia was studied in streptozotocin-diabetic and agematched control adult male rats. Rats made diabetic with a single intravenous injection of streptozotocin $(65 \mathrm{mg} / \mathrm{kg}) \mathrm{de}-$ veloped impaired glucagon and epinephrine responses to insulin-induced hypoglycaemia by $80-100$ days. Plasma glucagon levels in response to insulin-induced hypoglycaemia in streptozotocin-diabetic rats $(167 \pm 67 \mathrm{pg} / \mathrm{ml})$ were significantly lower $(p<0.01)$ than those in control rats $(929 \pm 272 \mathrm{pg} / \mathrm{ml})$. Similarly, plasma epinephrine levels in hypoglycaemic state in streptozotocin-diabetic rats $(11 \pm 8 \mathrm{pmol} / \mathrm{ml})$ were also significantly lower $(p<0.01)$ compared to control rats $(37 \pm 13 \mathrm{p} \mathrm{mol} / \mathrm{ml})$. Steptozotocin-diabetic rats provided with sodium salicylate $(25 \mathrm{mg} / 100 \mathrm{ml})$ in their drinking water from day one of diabetes exhibited prevention of the blunted gluca-
\end{abstract}

gon and epinephrine responses to insulin-induced hypoglycaemia. About 80-100 days after the chronic sodium salicylate treatment in streptozotocin-diabetic rats, both plasma glucagon levels $(1080 \pm 169 \mathrm{pg} / \mathrm{ml})$ and plasma epinephrine levels $(39 \pm 8 \mathrm{p} \mathrm{mol} / \mathrm{ml})$ were essentially identical to plasma glucagon levels $(1074 \pm 134 \mathrm{pg} / \mathrm{ml})$ and plasma epinephrine levels $(37 \pm 5 \mathrm{pmol} / \mathrm{ml})$ in control rats in hypoglycaemic state. These animals also exhibited an improvement in the diabetic state in that they had less severe hyperglycaemia and lack of weight gain. These results suggest that the blunted glucagon and epinephrine responses to insulin-induced hypoglycaemia may be related to altered prostaglandin levels in streptozotocin-diabetes.

Key words: Prostaglandins, diabetes, glucagon, epinephrine, hypoglycaemia, sodium salicylate.
Glucagon and epinephrine are the two major counterregulatory hormones secreted during hypoglycaemia. Secretion of these hormones in response to insulin-induced hypoglycaemia is impaired in diabetic patients and experimental diabetic rats although arginine infusion elicits normal secretion of glucagon in diabetes [1-7]. Although the exact mechanism of the secretory defect remains elusive, there appears to be an association with diabetic autonomic neuropathy [2-5].

Prostaglandins are believed to affect metabolic functions including the endocrine systems responsible for glucose homeostasis. Although a role for prostaglandins in insulin secretion is generally accepted, it is less clear if these substances are involved in glucagon secretion. There is evidence that acute infusion of sodium salicylate significantly increased glucagon and epinephrine secretion in response to insulin-induced hypoglycaemia in normal subjects [8]. Previous work from this labora- tory has shown that acute infusion of sodium salicylate normalises the impaired glucagon and epinephrine secretion in long-term streptozotocin-diabetic rats [9]. Similarly, Giugliano et al. [10] observed that, in diabetic patients with autonomic neuropathy, acute infusion of sodium salicylate normalised both the defects of blunted glucagon response to insulin-induced hypoglycaemia and the slowed rate of glucose recovery.

The purpose of this present study was to assess the effects of chronic sodium salicylate feeding on the impaired glucagon and epinephrine responses to insulininduced hypoglycaemia in long-term (80-100 days post-streptozotocin injection) streptozotocin-diabetic rats. Chronic sodium salicylate feeding to streptozotocin-diabetic rats from the day of the induction of diabetes prevented the defect of the impaired secretion of glucagon and epinephrine responses to insulin-induced hypoglycaemia. 


\section{Materials and methods}

\section{Animals and diets}

Male Sprague-Dawley rats with initial body weight between $250-300 \mathrm{~g}$ were used. Experimental diabetes was induced after an overnight fast by intravenous injection of streptozotocin (Sigma Co., St. Louis, Mo, USA), $65 \mathrm{mg} / \mathrm{kg}$ dissolved in citrate buffer $\mathrm{pH} 4.5$. The control rats received citrate buffer $\mathrm{pH} 4.5$ only. Animals were housed 3 per plastic cage in a thermostated room with a fixed $12 \mathrm{~h}$ artificial light-dark cycle. The rats had free access to water and were fed Purina Rat Chow. All rats injected with streptozotocin showed glycosuria within $24 \mathrm{~h}$. Only rats having plasma glucose levels above $16.7 \mathrm{mmol} / 1$ were designated as streptozotocin-diabetic and included in the study.

\section{Experimental protocol}

One day after the induction of diabetes both streptozotocin-diabetic and control rats were sub-divided into two groups. One group of both control and streptozotocin-diabetic rats was fed Purina Rat Chow and tap water ad libitum. The second group of both streptozotocin-diabetic and control rats was fed Purina Rat Chow and tap water containing sodium salicylate $(25 \mathrm{mg} / 100 \mathrm{ml})$ ad libitum. Of the twelve control and nine streptozotocin-diabetic rats treated with sodium salicylate, three streptozotocin-diabetic animals died during induction of hypoglycaemia. These rats died early in the experiment, probably from the anaesthetic. We have observed a hypersensitivity to chloral hydrate in streptozotocin-diabetic rats. Food and water consumption were measured daily. About $80-100$ days after the initiation of sodium salicylate feeding, insulin-induced hypoglycaemia was induced as follows: all rats were fasted and sodium salicylate was withdrawn prior to induction of hypoglycaemia to eliminate the circulating sodium salicylate during insulin-induced hypoglycaemia. The jugular vein (for infusion) and the carotid artery (for blood sampling) were cannulated under chloral hydrate anaesthesia $(350 \mathrm{mg} / \mathrm{kg}$ i. p.). A fasting blood sample $(2.0 \mathrm{ml})$ was collected with a heparinised syringe; $1.0 \mathrm{ml}$ was transferred into an ice-cold tube containing $50 \mu \mathrm{l}$ of Trasylol $(10,000 \mathrm{KIU} / \mathrm{ml})$ and EDTA $(1.2 \mathrm{mg} / \mathrm{tube})$ mixture (for glucagon) and the remaining $1.0 \mathrm{ml}$ was placed into a second ice-cold plain tube (for epinephrine). All blood samples were kept at $4^{\circ} \mathrm{C}$ until centrifuged. Plasma glucose (PG) levels were determined and insulin was injected $i . v$. as a bolus according to the following-formula: $2.0+(\mathrm{PG}-100) \times 0.02 \mathrm{U} / \mathrm{kg})$. Immediately after the bolus insulin injection via the jugular vein, insulin $\left(5 \mathrm{U} \cdot \mathrm{kg}^{-1} \cdot \mathrm{h}^{-1}\right)$ and chloral hydrate $\left(57.5 \mathrm{mg} \cdot \mathrm{kg}^{-1} \cdot \mathrm{h}^{-1}\right)$ were infused at a rate of $2.3 \mathrm{ml} / \mathrm{h}$. Approximately $50 \mu \mathrm{l}$ blood samples were collected periodically (maximum 15 times) to determine plasma glucose levels in order to monitor hypoglycaemia. A second blood sample $(2.0 \mathrm{ml})$ was collected when the plasma glucose level dropped to between $1.67-2.2 \mathrm{mmol} / 1$. As described above, the blood samples were transferred into ice-cold tubes for glucagon and epinephrine estimations. All blood samples were centrifuged at $1500 \times g$ at $4^{\circ} \mathrm{C}$ for $15 \mathrm{~min}$. Plasma samples were separated and stored at $-20^{\circ} \mathrm{C}$ for glucagon and at $-75^{\circ} \mathrm{C}$ for epinephrine determinations at a later date.

\section{Statistical analysis}

Plasma glucose concentrations were determined by the glucose oxidase method, using a glucose autoanalyser (Beckman Instruments, Fullerton, Calif., USA). Plasma glucagon was measured by radioimmunoassay [11] using crystalline porcine pancreatic glucagon as standard (Eli Lilly and Co., Indianapolis, Ind., USA). Both standards and samples were extracted with ice-cold acetone to eliminate "Big Plasma Glucagon" [12]. Plasma epinephrine levels were determined by high performance liquid chromatography with the electrochemical detection technique of Hallman et al. [13] as modified by Patel [7]. Statistical significance was computed by Duncan's multiple range test. Differences between means were considered statistically significant when $p$ was less than 0.05 .

\section{Results}

Rats in both control groups offered tap water with or without sodium salicylate consumed identical amounts of food and water. Similarly, there was no difference in food and water consumption between streptozotocindiabetic rats offered tap water with or without sodium salicylate.

Streptozotocin-diabetic rats required significantly more insulin $(p<0.01)$, compared to control animals, to induce identical hypoglycaemia (Table 1). Sodium salicylate treated control rats required significantly less insulin $(p<0.01)$, compared to untreated control rats, to induce identical hypoglycaemia. Similarly, sodium salicylate treated streptozotocin-diabetic rats required less insulin to induce hypoglycaemia compared to untreated streptozotocin-diabetic rats. However, this difference was not statistically different. The rate of fall of glucose was significantly faster $(p<0.01)$ in sodium salicylate treated control rats compared to untreated control rats. There was no difference in the rate of fall of glucose between sodium salicylate treated and untreated streptozotocin-diabetic rats. Fasting plasma glucose levels were essentially the same in control rats consuming tap water with or without sodium salicylate (Table 2). Fasting plasma glucose levels in streptozotocin-diabetic rats were significantly higher $(p<0.01)$ than those in control rats. However, fasting plasma glucose levels were lower in streptozotocin-diabetic rats

Table 1. Total amount of insulin infused and rate of fall of glucose during insulin infusion in sodium salicylate treated and untreated control and streptozotocin-diabetic rats

\begin{tabular}{lcl}
\hline Animals & $\begin{array}{l}\text { Total insulin } \\
\text { required to obtain } \\
\text { hypoglycaemia }(\mathrm{mg})\end{array}$ & $\begin{array}{l}\text { Rate of fall of } \\
\text { glucose } \\
(\mathrm{mg} / \mathrm{min})\end{array}$ \\
\hline $\begin{array}{l}\text { Control (9) without } \\
\text { sodium salicylate }\end{array}$ & $81.9 \pm 20.5$ & $2.23 \pm 0.04$ \\
$\begin{array}{l}\text { Control (12) with } \\
\text { sodium salicylate }\end{array}$ & $46.1 \pm 7.7^{\mathrm{a}}$ & $3.3 \pm 0.7^{\mathrm{a}}$ \\
$\begin{array}{l}\text { Long-term (9) } \\
\text { streptozotocin- } \\
\text { diabetic without } \\
\text { sodium salicylate }\end{array}$ & $164.6 \pm 46.6^{\mathrm{a}}$ & $2.92 \pm 1.31$ \\
$\begin{array}{l}\text { Long-term (6) } \\
\text { streptozotocin- } \\
\text { diabetic with } \\
\text { sodium salicylate }\end{array}$ & $140.3 \pm 15.4^{\mathrm{a}}$ & \\
\hline
\end{tabular}

Results are expressed as mean $\pm \mathrm{SD}()=$ number of animals observed. Sodium salicylate $(25 \mathrm{mg} / 100 \mathrm{ml})$ was offered in drinking water ad libitum from one day after the induction of diabetes. ${ }^{a} p<0.01$ compared to sodium salicylate untreated control animals 
Table 2. Effects of chronic sodium salicylate feeding on body weights, plasma glucose, glucagon, and epinephrine levels during intravenous insulin infusion in normal and long-term diabetic rats (80-100 days following streptozotocin)

\begin{tabular}{|c|c|c|c|c|c|c|c|}
\hline \multirow[t]{2}{*}{ Animals } & \multirow{2}{*}{$\begin{array}{l}\text { Body } \\
\text { weight } \\
\text { (g) }\end{array}$} & \multicolumn{2}{|l|}{$\begin{array}{l}\text { Glucose } \\
(\mathrm{mmol} / \mathrm{l})\end{array}$} & \multicolumn{2}{|l|}{$\begin{array}{l}\text { Glucagon } \\
\text { (pg/ml) }\end{array}$} & \multicolumn{2}{|c|}{$\begin{array}{l}\text { Epinephrine } \\
(\mathrm{pmol} / \mathrm{ml})\end{array}$} \\
\hline & & $\overline{\mathrm{I}}$ & $\mathrm{H}$ & I & $\mathrm{HI}$ & I & $\mathrm{H}$ \\
\hline $\begin{array}{l}\text { Control (12) with } \\
\text { sodium salicylate }\end{array}$ & $394 \pm 40$ & $8.7 \pm 1.39$ & $2.0 \pm 0.11$ & $36 \pm 10$ & $1074 \pm 134^{a}$ & $2 \pm 1$ & $37 \pm 5$ \\
\hline $\begin{array}{l}\text { Long-term (6) } \\
\text { diabetic with } \\
\text { sodium salicylate }\end{array}$ & $382 \pm 33^{b}$ & $16.4 \pm 2.28^{\mathrm{a}, \mathrm{b}}$ & $1.8 \pm 0.22$ & $96 \pm 18^{a}$ & $1080 \pm 169^{b}$ & $3 \pm 1$ & $9 \pm 8^{b}$ \\
\hline
\end{tabular}

All results are expressed as mean \pm SD. Number of animals observed are in parenthesis. $I=I$ initial, $H=$ Hypoglycaemic state. Sodium salicylate $(25 \mathrm{mg} / 100 \mathrm{ml})$ was offered in drinking water ad libitum from day one of diabetes. ${ }^{\mathrm{a}} p<0.01$ compared with control animals without sodium salicylate $;{ }^{b} p<0.01$ compared with long-term diabetic animals without sodium salicylate

drinking sodium salicylate water, compared to those in streptozotocin-diabetic rats consuming plain tap water. Fasting body weights of control groups either fed sodium salicylate or not were identical. Streptozotocindiabetic rats not treated with sodium salicylate had significantly lower $(p<0.01)$ fasting body weights compared to control, as well as, streptozotocin-diabetic rats fed sodium salicylate. Sodium salicylate feeding prevented the loss in body weights generally observed in streptozotocin-diabetic rats. This indicates that chronic sodium salicylate feeding improves streptozotocin-diabetes.

Glucagon and epinephrine levels during hypoglycaemic states in control rats consuming tap water with or without sodium salicylate were almost identical (Table 2). Glucagon and epinephrine levels in hypoglycaemic states for streptozotocin-diabetic rats drinking tap water only, were significantly lower $(p<0.01)$ than those in control rats. However, glucagon and epinephrine levels in hypoglycaemic states were significantly higher $(p<0.01)$ in streptozotocin-diabetic rats fed tap water with sodium salicylate compared to those in streptozotocin-diabetic rats fed tap water without sodium salicylate. Furthermore, glucagon and epinephrine levels in streptozotocin-diabetic rats consuming sodium salicylate were not significantly different from those in control rats. This suggests that the chronic sodium salicylate feeding to streptozotocin-diabetic rats from one day after the induction of diabetes prevents the inhibition of the secretion of glucagon and epinephrine in response to insulin-induced hypoglycaemia.

The correlation between fasting plasma glucose and hypoglycaemia stimulated counter-regulatory hormone secretion, as well as the effect of sodium salicylate, were computed using linear regression analysis. Fasting plasma glucose levels of control and streptozotocin-diabetic rats without sodium salicylate feeding were regressed against hypoglycaemia-stimulated glucagon and epinephrine secretion. The correlation coefficient for glucagon secretion was negatively correlated $(r=-0.88)$ for streptozotocin-diabetic rats. This was significantly different from that in control rats $(r=-0.1)$. Similarly, it has been reported that there is a statistically significant $(p<0.005)$ negative correlation $(r=-0.705)$ between the rise of glucagon due to insulin-induced hypoglycaemia and duration of streptozotocin-diabetes [7]. The actual values of glucagon (based on this regression) of control sodium salicylate fed rats differed by a mean value of 148 from the predicted values ( $16 \%$ higher). On the other hand, the actual values of glucagon in streptozotocin-diabetic rats fed sodium salicylate differed by a mean value of 419 from the predicted value $(63 \%$ higher). Similarly, predicted values for epinephrine secretion in sodium salicylate-fed control and streptozotocin-diabetic rats were calculated from the respective regression line of rats fed no sodium salicylate. There was no difference between the predicted and actual values for control rats. However, the actual values for streptozotocin-diabetic rats were almost twice the predicted values. These results suggest that sodium salicylate treatment improves the counter-regulatory hormone responses to insulin-induced hypoglycaemia in long-term streptozotocin-diabetic rats unrelated to the improvement in plasma glucose levels.

\section{Discussion}

The chronic sodium salicylate treatment significantly improved loss of body weight and hyperglycaemia in streptozotocin-diabetic rats. Similar beneficial effects of sodium salicylate in human diabetes mellitus were reported by Williamson [14] in the beginning of this century. Micossi et al. [15] have shown that chronic acetylsalicylic acid administration lowers plasma glu- 
cose and increases plasma insulin levels in normal and non-insulin-dependent diabetic patients. The mechanism of acetylsalicylic acid action is controversial [16, 17], although it presumably involves an effect on prostaglandin synthesis [18, 19]. Prostaglandins and prostaglandin inhibitors are known to influence the secretion of a number of hormones [20]. Sodium salicylate increases the insulin response to a glucose load in Type 2 (non-insulin-dependent) diabetic patients [21]. Therefore, the improvement in the body weights and plasma glucose in streptozotocin-diabetic rats after chronic sodium salicylate feeding might be due to insulin secretion from the residual B cells, as well as, from extrapancreatic cells such as parotid and submaxillary glands [22]. This was not substantiated in the present study as plasma insulin levels, as well as, plasma glucose levels were not determined during the chronic sodium salicylate feeding. Furthermore, salicylates directly affect the increase of glucose utilisation by peripheral tissue, as well as, inhibit the gluconeogenesis from various metabolic intermediates [23].

Acute infusion of sodium salicylate with insulin has been reported to normalise the impaired glucagon in diabetic patients [10] and experimental diabetic rats [9]. These studies have suggested that the prostaglandin inhibitory effects of sodium salicylate are responsible for the improved counter-regulatory responses in diabetes. It has been demonstrated that endogenous prostaglandin synthesis is elevated in the diabetic state. Haluska et al. [24] have reported increased synthesis of prostaglandin E-like material during platelet aggregation in adults with diabetes compared to control subjects. Chase et al. [25] also have demonstrated that prostaglandin $\mathrm{E}$ and prostaglandin $\mathrm{F} 2$ production were significantly elevated in blood from children with diabetes mellitus. Prostaglandins have been reported to exert a modulating action on the secretion of various hormones [26-29].

The modulation, by prostaglandins, of the release of norepinephrine from adrenergic nerve endings during stimulation of sympathetic nerve is well documented [30, 31]. As regards cholinergic nerves, however, the role of prostaglandins in the release of acetylcholine is still controversial. In the isolated ileum or colon, prostaglandins of the E series produce contractions which are reduced by tetrodotoxin or muscarinic receptor antagonists, while cholinesterase inhibitors augment these responses [32-34]. Prostaglandin E reversibly antagonised negative chronotropic responses to vagal stimulation in the isolated perfused heart, but did not alter similar myocardial effects produced by exogenous acetylcholine [35]. These observations suggest that prostaglandins are capable of interacting with some cholinergic neurons to either facilitate or inhibit acetylcholine release. Previous work from this laboratory has demonstrated that the parasympathetic nervous system plays an important role in glucagon secretion in response to insulin-induced hy- poglycaemia in rats [36]. The lack of glucagon response to insulin-induced hypoglycaemia observed in longterm streptozotocin-diabetic rats could be due to a possible deterioration of the parasympathetic nervous system, since acute carbachol infusion could normalise the blunted glucagon and epinephrine responses to insulin-induced hypoglycaemia in long-term streptozocin-diabetic rats. This is further confirmed by our recent studies in which we demonstrated that glucagon secretion in response to left cervical vagus nerve stimulation is also impaired in streptozotocin-diabetic rats [37]. In the present study, parasympathetic neuropathy in streptozotocin-diabetic rats was not assessed. However, streptozotocin-diabetic rats exhibited typical symptoms of neuropathy such as urinary bladder and colon distention and diarrhea. In the present study, chronic feeding of sodium salicylate prevented the impairment of counter-regulatory hormone secretion in long-term streptozotocin-diabetic rats. Therefore, sodium salicylate may reduce cholinergic deterioration and, thereby, prevent the impairment of glucagon and epinephrine responses to insulin-induced hypoglycaemia in long-term streptozotocin-diabetic rats. In contrast to this, several studies have reported that the impaired glucagon response to insulin-induced hypoglycaemia is not associated with either sympathetic or parasympathetic neuropathy [38-41]. Gerich et al. [1] have suggested that the abnormalities of glucagon secretion in response to glycaemic changes in diabetes mellitus are related to some genetically influenced primary defect of the pancreatic alpha-cell in glucose recognition and not to the glucagon releasing mechanism. Robertson and Porte [42] also reported that a glucoserecognising defect in the islets of Langerhans probably impairs glucagon secretion, as well as insulin secretion in diabetic patients. However, this defect may not mainly be genetically influenced because streptozotocin-diabetic rats also show an impaired glucagon response to insulin-induced hypoglycaemia. Therefore, sodium salicylate may also affect this defect of glucose recognition by the pancreatic alpha-cells. The mechanism of this is not known, but a further investigation may reveal the exact mechanism.

Chronic sodium salicylate feeding improved the diabetic state as observed in this study by the improvement in body weight loss, as well as, hyperglycaemia. This may also be one of the factors for the normal counter-regulatory hormones response to insulin-induced hypoglycaemia. A previous report [43] from this laboratory in streptozotocin-diabetic rats has demonstrated that the blunted epinephrine response to insulininduced hypoglycaemia was normalised after prolonged insulin treatment, but we found only partial improvement in the lack of glucagon response to insulin-induced hypoglycaemia. Bolli et al. [44] similarly found that intensive insulin therapy only partially restored the impaired glucagon response in Type I (insulin-dependent) diabetic patients. Therefore, the im- 
provement in the diabetic state by chronic sodium salicylate treatment may only be partially responsible for the reversal of the altered counter-regulatory hormone responses. Further studies with the combined therapy of insulin pump and chronic sodium salicylate will be essential to understand the exact mechanisms of how sodium salicylate improves the altered counterregulatory hormones responses to insulin-induced hypoglycaemia in diabetes.

In normal rats, the drop in plasma glucose to $1.67-2.2 \mathrm{mmol} / 1$ induces maximum glucagon response. Therefore, in the present study we examined the glucagon response to insulin-induced hypoglycaemia at plasma glucose $1.67-2.2 \mathrm{mmol} / \mathrm{l}$. It is possible that in streptozotocin-diabetic rats the maximum glucagon response may occur at lower plasma glucose levels. However, plasma glucose levels lower than $1.67 \mathrm{mmol} / 1$ rapidly results in the death of the animals. Therefore, it was not possible to conclude whether sodium salicylate feeding affected the timing of the peak counter-regulatory hormone response. However, as we compared our results for each group at the nadir glucose levels, it is possible to conclude that counter-regulatory hormone response at nadir were different in these groups.

Furthermore, the basal plasma glucose levels in control animals were significantly lower than those in streptozotocin-diabetic rats. Therefore, the amount of insulin required to attain an almost identical nadir plasma glucose levels in streptozotocin-diabetic rats treated with or without sodium salicylate was significantly higher than that for respective control rats. This raises a valid question whether the greater amount of insulin administered to streptozotocin-diabetic rats may have suppressed the $\alpha$-cells, and, thereby, glucagon secretion in hypoglycaemic state in long-term steptozotocindiabetic rats was impaired. However, this could not be true as the total amounts of insulin required to achieve an identical hypoglycaemia in sodium salicylate treated and untreated streptozotocin-diabetic rats were not different, but there was a significant difference in the glucagon response to insulin-induced hypoglycaemia. Furthermore, Unger et al. [45] have suggested that insulin-induced hypoglycaemia is a very powerful stimulus to glucagon secretion despite pharmacological levels of circulating insulin.

In conclusion, chronic sodium salicylate administration improved the blunted glucagon and epinephrine responses to insulin-induced hypoglycaemia in longterm diabetic rats. Sodium salicylate may affect the diabetic state, as well as, endogenous prostaglandin synthesis, which may be a possible factor to thwart the progression of the parasympathetic neuropathy in longterm diabetic rats.

Acknowledgements. The expert technical assistance of D. Bruch is gratefully acknowledged and sincere thanks are due to Ms. D. Taylor for secretarial help. This work was supported by the Kroc Foundation.

\section{References}

1. Gerich JE, Langlois M, Noacco C, Karam JM, Forsham PM (1973) Lack of glucagon response to hypoglycaemia in diabetics: evidence of an intrinsic pancreatic alpha-cell defect. Science 182: 171-173

2. Mather TD, Tanenberg RJ, Greenberg BL, Hoffman JE, Doe RP, Goetz FC (1977) Lack of glucagon response to hypoglycaemia in diabetic autonomic neuropathy. Diabetes 26: 196-200

3. Levitt NS, Vinik AI, Sive AA, Child P, Jackson WPO (1979) Studies on plasma glucagon concentration in maturity-onset diabetics with autonomic neuropathy. Diabetes 28: 1015-1021

4. Hilsted J, Madsbad S, Krarup T, Sestoft L, Christensen NJ, Troniej B, Galbo H (1981) Hormonal, metabolic and cardiovascular responses to hypoglycaemia in diabetic autonomic neuropathy. Diabetes 30: 626-633

5. Hilsted J, Madsbad S, Krarup T, Tronier B, Galbo H, Sestoft L, Schwartz TW (1982) No response of pancreatic hormones to hypoglycaemia in diabetic neuropathy. J Clin Endocrinol Metab 54: 815-819

6. Lykkelund C, Lund ED (1979) Plasma glucagon responses to insulin induced hypoglycaemia and arginine in normal and alloxan diabetic rats. Scand J Clin Lab Invest 39: 151-157

7. Patel DG (1983) Lack of glucagon response to hypoglycaemia in long-term experimental diabetic rats. Diabetes 32: 55-60

8. Metz S, Halter J, Robertson RP (1980) Sodium salicylates potentiates neurohumoral responses to insulin-induced hypoglycaemia. J Clin Endocrinol Metab 51: 93-100

9. Patel DG, Recckio RA (1983) Sodium salicylate normalizes impaired glucagon response to insulin-hypoglycaemia in long-term diabetic rats. Diabetes 32 [Suppl 1]: 143A

10. Giugliano D, Giannetti G, DiPinto P, Cerciello T, Ceriello A, D'Onofrio F (1985) Normalization by sodium salicylate of the impaired counterregulatory glucagon response to hypoglycaemia in insulin-dependent diabetes, a possible role for endogenous prostaglandins. Diabetes 34: 521-525

11. Faloona GR, Unger RH (1974) Glucagon. In: Jaffe BM, Behram MR (eds) Methods of hormone radioimmunoassay. Academic Press, New York, pp 317-330

12. von Schenck H, Nilsson OR (1981) Radioimmunoassay of extracted glucagon compared with three non-extraction assays. Clin Chem 109: 183-191

13. Hallman H, Fornebo LO, Hamberger B, Jonsson G (1978) A sensitive method for time determination of plasma catecholamines using liquid chromatography with electrochemical detection. Life Sci 23: 1049-1052

14. Williamson RT (1901) On the treatment of glycosuria and diabetes mellitus with sodium salicylate. $\mathrm{Br}$ Med J 1: 760-762

15. Micossi P, Pontiovoli AE, Baron SH, Tamayo RC, Lengel F, Bevlacqua M, Rabbi V, Rorbiato G, Foa PP (1978) Aspirin stimulates insulin and glucagon secretion and increases glucose tolerance in normal and diabetic subjects. Diabetes 27: 1196-1204

16. Manchester KL, Randle PJ, Howard-Smith G (1958) Some effects of sodium salicylate on muscle metabolism. Br Med $J 1$ : $1028-1230$

17. Torella R, Giugliano D, Siniscalchio N, Sgambato S, D'Onofrio F (1979) Influence of acetylsalicylic acid on plasma glucose, insulin, glucagon and growth hormone levels following tobutamide stimulation in man. Metabolism 28: 887 889

18. Ferreira SH, Moncada S, Vane JR (1971) Indomethacin and aspirin abolish prostaglandin release from the spleen. Nature 231: 237-239

19. Vane JR (1971) Inhibition of prostaglandin synthesis as a mechanism of action for aspirin-like drugs. Nature 231: 232-235

20. Horton EW (1972) Prostaglandins. Springer, Berlin Heidelberg New York

21. Robertson RP, Chen M (1977) A role of prostaglandin E in defective insulin secretion and carbohydrate intolerance in diabetes mellitus. J Clin Invest 60: 747-753

22. Smith PH, Patel DG (1984) Immunochemical studies of the in- 
sulin-like material in the parotid gland of rats. Diabetes 33: 661-666

23. Woodbury DM, Fingl E (1975) Analgesic-antipyretics, antiinflammatory agents, and drugs employed in the therapy of gout. In: Goodman LS, Gilman A (eds) The Pharmacological Basis of Therapeutics. McMillan, New York, pp 325-358

24. Halushka PU, Lurie D, Colwell JA (1977) Increased synthesis of prostaglandin-E-like material by platelets from patients with diabetes mellitus. N Engl J Med 297: 1306-1311

25. Chase P, Williams RL, Dupont J (1979) Increased prostaglandin synthesis in childhood diabetes mellitus. J Pediatr 94: 185-189

26. Pek S, Tai TY, Elster A (1978) Stimulatory effects of prostaglandins $E_{1}$, and $F_{2}$ alpha on glucagon and insulin release in vitro. Diabetes 27: 801-809

27. Luyckx AS, Lefebvre PJ (1978) Possible role of endogenous prostaglandins in glucagon secretion by isolated Guinea-pig islets. Diabetologia 15: 411-416

28. Brody MJ, Kadowitz PJ (1974) Prostaglandins as modulators of the autonomic nervous system. Fed Proc 33:48-60

29. Hedqvist P (1977) Basic mechanisms of prostaglandin action on autonomic neurotransmission. Ann Rev Pharmacol Toxicol 17: 259-279

30. Hedquist P (1970) Antagonism by calcium of the inhibitory action of prostaglandin $E_{2}$ on sympathetic neurotransmission in the cat spleen. Acta Physiol Scand 80: 269-275

31. Hedqvist P, StJarne L, Wennmalm A (1970) Inhibition by prostaglandin $E_{2}$ of sympathetic neurotransmission in the rabbit heart. Acta Physiol Scand 79: 139-141

32. Harry JD (1968) The action of prostaglandin $E_{1}$ on the guinea pig isolated intestine. Br J Pharmacol 33:213 P

33. Bennett A, Eley KG, Scholes GB (1968) Effects of $P \mathrm{PE}_{1}$ and $\mathrm{E}_{2}$ on human, guinea pig and rat isolated small intestine. Br J Pharmacol 34: 630

34. Bennett A, Fleshler B (1969) Actions of $\mathrm{PGE}_{1}$ on the longitudinal muscle of the guinea pig isolated colon. Br J Pharmacol 35:351 P

35. Wennmalm A, Hedqvist $P$ (1971) Inhibition by prostaglandin $E_{1}$ of parasympathetic neurotransmission in the rabbit heart. Life Sci 10: $465-470$

36. Patel DG (1984) Role of parasympathetic nervous system in glucagon response to insulin-hypoglycaemia in normal and diabetic rats. Metabolism 33: 1123-1127

37. Patel DG, Skau KA (1988) Determination of vagal-stimulated glucagon release in diabetic rats. FASEB J 2: A1594
38. Cryer PE, Gerich JE (1985) Glucose counter regulation, hypoglycemia, and intensive insulin therapy in diabetes mellitus. $\mathrm{N}$ Engl J Med 313: 232-241

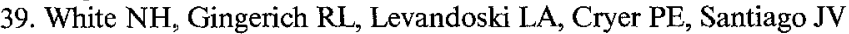
(1985) Plasma pancreatic polypeptide response to insulin-induced hypoglycemia as a marker for defective glucose counterregulation in insulin-dependent diabetes mellitus. Diabetes 34: 870-875

40. Kennedy FE, Bolli GB, Go VL, Cryer PE, Gerich JE (1987) The significance of impaired pancreatic polypeptide and epinephrine responses to hypoglycemia in patients with insulin-dependent diabetes mellitus. J Clin Endocrinol Metab 64: 602-608

41. Diem P, Abid M, Sutherland DER, Robertson RP (1988) Effects of denervated pancreas transplantation on glucagon and pancreatic polypeptide secretion in Type I diabetic recipients. 37 [Suppl 1]: 11A

42. Robertson RP, Porte DP Jr (1973) The glucose receptor. A defective mechanism in diabetes mellitus distinct from the betaadrenergic receptor. J Clin Invest 52: 870-876

43. Patel DG (1983) Effect of prolonged insulin treatment on blunted plasma catecholamine and glucagon increase during insulin hypoglycaemia in streptozotocin diabetic tats. Metabolism 32: 377-381

44. Bolli G, Calabrese G, DeFeo P, Compagnucci P, Zega G, Angeletti ZG, Cartechini MG, Santeusanio F, Brunetti P (1982) Lack of glucagon response in glucose counterregulation in Type 1 (insulin dependent) diabetics: absence of recovery after prolonged optimal insulin therapy. Diabetologia 22: 100-105

45. Unger RH, Lefebvre PJ (1972) Glucagon Physiology. In: Lefebvre PJ, Unger RH (eds) Glucagon, molecular physiology, clinical and therapeutic implications. Pergamon Press, Oxford, pp 213-244

Received: 27 May 1988

and in revised form: 3 November 1988

Dr. D.G. Patel

Division of Pharmacology and Medicinal Chemistry

College of Pharmacy

University of Cincinnati Medical Center

3223 Eden Avenue

Cincinnati, Ohio 45267-0004

USA 